\title{
Editorial statement: The first year of the European Journal of Government and Economics
}

Diego Varela, University of A Coruña, Spain

Giacomo Benedetto, Royal Holloway, University of London, United Kingdom

Jose Manuel Sanchez-Santos, University of A Coruña, Spain

\begin{abstract}
In this editorial statement we present a balance of the first year of life of the European Journal of Government and Economics. We discuss the main developments that concern the journal's indexation by academic databases. We also comment on the approval of a code of publication ethics and malpractice. Finally, we emphasise the dangers of excessive technical sophistication and the need to keep an integrated approach between the fields of political science and economics, according to the spirit of the journal.
\end{abstract}

JEL classification

A11; A12; L17

Keywords

Academic journal; economics, indexing; open access; political science 
With the publication of this second issue, it is a good time to present a balance of the first year of the journal. We thought that an editorial statement might be a good way to communicate with our fellow editorial board members, authors and readers.

There have been some substantial changes since the first issue was published in June. We obtained an ISSN and took the first steps for indexation of our journal's contents. The purpose was to increase the visibility and ease of use of the journal, thereby promoting its potential impact (see Varela, 2012). These efforts gave some early fruits, and our journal contents are already indexed by Google Scholar, RePEc, Worldcat and Bielefeld Academic Search.

Another index that we would like to join but is taking longer than expected is the Directory of Open Access Journals (DOAJ). A particularity of this index, as its name indicates, is that it only lists journals that use a funding model that does not charge readers or their institutions for access. Other than that, the formal requirements are that journals must have an ISSN and at least five research papers published. In practice, however, there is another factor that is making this an increasingly selective index.

The DOAJ itself is not only open access, but nor does it charge indexed journals or publishers. As a consequence, there is great demand from journals to join this index, which cannot always be met by the limited staff at Lund University in Sweden, which is currently responsible for the maintenance of the index. As a result, there is backlog of journals to be indexed, among which EJGE. This is a particular instance of rationing by waiting (see Barzel, 1974), in which waiting can exclude new projects that do not have a firm vocation of continuity. Other established indices, such as Econlit, which used to be a very popular index in economics, the ISI Web of Science, or Scopus, also require a publication record of two or three years prior to indexation. The difference with the DOAJ is that the waiting periods and associated publication record requirements are not fixed but endogenous.

In addition to the traditional requirements about periodicity and peer review, Scopus also requires journals to publish a statement about their publication ethics and malpractice policy. We have published such a statement on our website, in which we cover the duties of authors, reviewers, and editors, and deal with issues such as replicability, acknowledgement of sources or conflicts of interest (EJGE, 2012). Writing this formal statement, basing ourselves on the experience of other major journals, publishers and associations, made us reflect about some of those important issues. This experience, which we initially thought of as merely a formal requirement, proved helpful when preparing this second issue, which includes an article about legislator shirking that is based on experiments with human subjects.

The nine research papers included in the first volume of this journal include a fair geographical representation. Our authors have come from Germany, Belgium, the US, the UK, France, Spain, Norway, Italy, and Hungary. So far as topics are concerned, we have covered many important issues, most of which are about the link between government and economics and thus can be of potential interest to political scientists and economists alike. However, we are somewhat concerned that the methodological differences between economists and political scientists may be creating an undesirable cleavage between both traditions, which we would like to avoid. In particular, some of the articles have a high component of technical sophistication, which may be discouraging some readers and potential authors.

We believe that it is important to have a high standard of analytic rigour, but also think that technical sophistication should not be an end in itself. Therefore, we would like authors to make an effort to convey their messages in a way that can be understood by less technically oriented readers. This view is consistent with that of some prominent economists that see a dangerous slip in their discipline. As Steven Levitt points out: 
There's a lot of intellectual firepower going into economics today. At the same time, I think the profession has gone off the rails. The fetishistic infatuation with technicality and mathematical difficutlty is extremely unhealthy... I think that will make us increasingly irrelevant to the real world (Interview with Levitt in Bowmaker, 2012: 246-7).

Therefore, we shall make an effort to reduce the unnecessary technical oversophistication of published papers, while retaining analytical rigour. We wish to encourage more political scientists to make submissions to our journal, which may require a rewording of the journal's aims and scope. We believe this will focus the papers on important questions, and help reduce the current cleavage between economists and political scientists that goes against the spirit of our journal and social science in general.

\section{References}

Barzel, Yoram (1974) 'A theory of rationing by waiting', Journal of Law and Economics 17(1): 73-95.

EJGE (2012) 'Editorial Policies', URL (consulted Dec. 2012): http://www.ejge.org/index.php/ejge/about/editorialPolicies.

Bowmaker, Simon W. (2012) The art and practice of economics today: Lessons from leading minds. Cheltenham: Edward Elgar.

Varela, Diego (2012) 'The contribution of ISI indexing to a papers' citations: results of a natural experiment', European Political Science advance online publication 5 October 2012, URL: http://dx.doi.org/10.1057/eps.2012.29. 